\title{
PEMBELAJARAN BAHASA ARAB DENGAN METODE $A L-$ 'ARABIYA BAINA YADAIKA DI MA'HAD ALI BIN ABI THALIB UNIVERSITAS MUHAMMADIYAH YOGYAKARTA
}

\author{
Aziz Abdullah dan Purwoko \\ Sekolah Tinggi Agama Islam masjid Syuhada Yogyakarta \\ staimsyogyakarta@yahoo.co.id
}

\section{Abstrak}

Penelitian ini bertujuan untuk mengetahui pembelajaran bahasa arab dengan metode Al-'Arabiyah Baina Yadaika, hasil yang dicapai, faktor pendukung dan faktor penghambatnya. Penelitian ini diklasifikasikan sebagai penelitian yang menggunakan pendekatan metode analisis deskriptif kualitatif dan analisis kuantitatif. Subyek penelitian ini adalah mudir ma'had, asatidz ma'had dan mahasiswa mustawa tamhidy Ma'had Ali Bin Abi Tholib Universitas Muhammadiyah Yogyakarta. Teknik pengumpulan datanya menggunakan metode observasi, metode wawancara, metode dokumentasi dan metode angket.

Berdasarkan penelitian yang penulis lakukan menunjukan bahwa pembelajaran bahasa arab metode Al-'Arobiyah Baina Yadaika adalah untuk pemula dengan menekankan pada ketrampilan mendengar, membaca, berbicara dan menulis. Hasil yang dicapai adalah baik berdasarkan analisis data yang menunjukan nilai kategori baik paling tinggi yaitu $50 \%$, dan kategori sangat baik 11,54\% serta kategori kurang baik adalah $38,46 \%$. Faktor pendukung dalam pembelajaran bahasa arab metode Al-'Arobiyah Baina Yadaikaadalah lokasi ma'had yang kondusif. Sedang yang menjadi faktor penghambatnya adalah media pembelajaran yang belum lengkap dan mahasiswa yang kurang aktif.

Kata kunci: Pembelajaran Bahasa Arab, Al-'Arabiyah Baina Yadaik 
Aziz Abdullah dan Purwoko : Pembelajaran Bahasa Arab Dengan Metode Al-'Arabiya Baina Yadaika Di Ma'had Ali Bin Abi Thalib Universitas Muhammadiyah Yogyakarta

\section{Abstract}

This study aims to determine the learning of arabic language with Al-'Arabiyah Baina Yadaika method, the results achieved, supporting factors and inhibiting factors. This research is classified as research using qualitative descriptive analysis method approach and quantitative analysis. The subject of this research is mudir ma'had, asatidz ma'had and student of mustawa tamhidy Ma'had Ali Bin Abi Tholib Muhammadiyah University of Yogyakarta. The data collection technique uses observation method, interview method, documentation method and questionnaire method.

Based on the research that the authors do show that the Arabic language learning method Al-'Arobiyah Baina Yadaika is for beginners with emphasis on the skills of listening, reading, speaking and writing. The results achieved are good based on data analysis showing the highest good category category is $50 \%$, and the category is very good $11.54 \%$ and the less good category is $38.46 \%$. The supporting factor in Arabic language learning Al-'Arobiyah Baina Yadaika method is the location of conducive ma'had. Being the inhibiting factor is an incomplete learning media and students who are less active.

Keywods :

\section{A. Pendahuluan}

Bahasa Arab memiliki kaitan yang sangat erat dengan agama Islam, karena semua ajaran Islam terhimpun dalam alQur'an dan dilengkapi dengan penjelasan al-Hadits. Untuk dapat mengkaji dan mendalami ajaran Islam, harus mempelajari al-Qur'an dan al-Hadits, dan agar dapat 
mempelajari al-Qur'an dan al-Hadits dibutuhkan kemampuan berbahasa Arab yang memadai. ${ }^{68}$

PembelajaranbahasaArabselama ini masih menghadapi berbagai kendala diantaranya adalah munculnya berbagai kesulitan dalam proses pembelajaran bahasa Arab. Asumsi yang berkembang bahwa diantaranya disebabkan oleh alokasi waktu pembelajaran yang belum mencukupi, kurang tersedianya fasilitas belajar bahasa Arab di rumah, mahasiswa belum mampu mendudukkan bahasa Arab yang dipelajarinya dalam kehidupan sehari-hari, buku-buku bahasa Arab atau buku-buku yang berkaitan dengan bahasa Arab kurang mendapat perhatian mahasiswa.

Mahasiswa belum terbiasa menggunakan bahasa Arab di dalam kelas, serta adanya kesan bahwa mata kuliah bahasa Arab itu sulit bahkan lebih sulit dari bahasa asing lainnya. Tidak adanya lingkungan berbahasa Arab juga menjadi kendala dalam pembelajaran bahasa. Padahal lingkungan berbahasa memiliki peran yang sangat penting dalam mendukung pembelajaran bahasa Arab. Faktor-faktor di atas yang menjadi kendala dalam proses pembelajaran bahasa arab adalah rendahnya minat mahasiswa terhadap mata kuliah bahasa Arab. Hal ini dapat dilihat dari sedikitnya mahasiswa yang mengikuti pembelajaranbahasa Arab dima'had atau di kampus. 
Aziz Abdullah dan Purwoko : Pembelajaran Bahasa Arab Dengan Metode Al-'Arabiya Baina Yadaika Di Ma'had Ali Bin Abi Thalib Universitas Muhammadiyah Yogyakarta

Lembaga Pendidikan Bahasa Arab dan Studi Islam Ali Bin Abi Thalib, atau yang lebih populer disebut "Ma'had alLughah"merupakanlembagayangmemfokuskan pendidikan bahasa arab. Lembaga ini merupakan lembaga kerjasama di bidang pendidikan antaraAsia Muslim Charity Foundation(AMCF)Jakarta denganUniversitas MuhammadiyahYogyakarta (UMY). Metode pembelajaran bahasa arab yang digunakan salah satunya adalah metode $\mathrm{Al}$ 'Arabiyah Baina Yadaika.

Berdasarkan uraian latar belakang yang telah dituliskan diatas, penulis merumuskan beberapa permasalahan yang menjadi pokok pembahasan penelitian ini, adalah :

1. Bagaimana pembelajaranbahasa arab dengan metode $A l$ 'Arabiyah Baina Yadaika di ma'had Ali Bin Abi Tholib Universitas Muhammadiyah Yogyakarta?

2. Bagaimana hasil yang dicapai mahasiswa dalam pembelajaran bahasa arab dengan metode Al-'Arabiyah Baina Yadaika di ma'had Ali Bin Abi Tholib Universitas Muhammadiyah Yogyakarta?

\section{B. Tujuan Penelitian}

Penelitian akan memiliki arti dan mendatangkan manfaat apabila mempunyai tujuan yang jelas, tujuan yang ingin dicapai dari penelitian ini adalah : 
1. Untuk mengetahui pembelajaran bahasa arab dengan metode Al-'Arabiyah Baina Yadaika di ma'had Ali Bin Abi Tholib Universitas Muhammadiyah Yogyakarta .

2. Untuk mengetahui hasil yang dicapai dalam pembelajaran bahasa arab dengan metode Al-'Arabiyah Baina Yadaika di ma'had Ali Bin Abi Tholib Universitas Muhammadiyah Yogyakarta.

\section{Kegunaan Penelitian}

Dalam penelitian ini diharapkan berguna untuk:

1. Memberikan sumbangan pemikiran terhadap para pendidik pada umumnya dan para guru bahasa arab khususnya.

2. Memberikan sumbangan pengetahuan pada pembelajaran bahasa arab dengan metode Al-'Arabiyah Baina Yadaikakhususnya di ma'had Ali Bin Abi Tholib Universitas Muhammadiyah Yogyakarta dan kaum muslimin pada umumnya.

\section{Metode Penelitian}

1. Metode Pengumpulan Data

Metode pengumpulan data yang digunakan dalam penelitian ini, adalah : 
Aziz Abdullah dan Purwoko : Pembelajaran Bahasa Arab Dengan Metode Al-'Arabiya Baina Yadaika Di Ma'had Ali Bin Abi Thalib Universitas Muhammadiyah Yogyakarta

\section{a. Metode Observasi}

Observasi adalah melakukan pencatatan dan pengamatan dengan sistematis terhadap fenomenafenomena yang diselidiki. ${ }^{69}$ Metode observasi merupakan teknik pengumpulan data, dimana peneliti melakukan pengamatan secara langsung ke obyek penelitian untuk melihat dari dekat kegiatan yang dilakukan.

b. Metode Wawancara (Interview)

Wawancara adalahcara mengumpulkan data melalui tanya jawab secara langsung berhadapan muka antara peneliti dengan informan untuk mengungkap data yang diperlukan. ${ }^{70}$ Wawancara merupakan metode pemgambilan data dengan cara menanyakan sesuatu kepada seseorang yang menjadi informan atau responden. Caranya adalah dengan cara bercakap-cakap secara tatap muka.

Jenis wawancara yang digunakan adalah wawancara bebas terpimpin dengan wawancara tak terpimpin, yaitu gabungan antara wawancara terpimpin dengan wawancara tidak terpimpin. Dalam teknis pelaksanaannya penulis mengajukan pertanyaan kepada informan, kemudian informan diminta menjawab bebas terbuka.

${ }^{69}$ Suharsimi Arikunto, Prosedur Penelitian Suatu Pendekatan Praktek, (Jakarta : Rineka Cipta, 1998), hlm. 120.

70 Suharsimi Arikunto, Op. Cit, hlm. 146 
Metode ini digunakan untuk mengumpulkan data tentang pembelajaran bahasa arab dengan metode Al-'Arabiya Baina Yadaika di ma'had Ali Bin Abi Tholib Universitas Muhammadiyah Yogyakarta, faktor pendukung dan faktor penghambatnya.

c. Metode Dokumentasi

Dokumentasi dari asal katanya dokumen yangartinya barang-barang tertulis dalam melaksanakan metode dokumentasi, peneliti menyelidiki benda-benda tertulis seperti buku-buku, majalah, dokumen, peraturanperaturan, notulen rapat, catatan harian dan sebagainya. ${ }^{71}$

Metode ini digunakan untuk memperoleh data tentang :

1) Gambaran umum ma'had Ali Bin Abi Tholib Universitas Muhammadiyah Yogyakarta.

2) Sarana dan prasarana yang dimiliki

3) Datadosen, mahasiswa, dan karyawan.

d. Metode Angket

Angket atau kuesioner adalah daftar pertanyaan yang dikirimkan langsung kepada orang yang ingin dimintai pendapat dan keyakinannya, untuk dimintai

71 Suharsimi Arikunto, Prosedur Penelitian Suatu Pendekatan Praktek (Jakarta: PT. Rineka Cipta), hlm.236. 
Aziz Abdullah dan Purwoko : Pembelajaran Bahasa Arab Dengan Metode Al-'Arabiya Baina Yadaika Di Ma'had Ali Bin Abi Thalib Universitas Muhammadiyah Yogyakarta

keterangan tentang keadaan dirinya sendiri. ${ }^{72}$ Metode ini digunakan penulis untuk memperoleh data tentang hasil yang dicapai dalam pembelajaran bahasa arab dengan metode Al-'Arabiyah Baina Yadaika di ma'had Ali Bin Abi Tholib Universitas Muhammadiyah Yogyakarta.

\section{Metode Analisis Data}

Metode analisis data sebagai suatu cara menganalisis data yang telah terkumpul untuk lebih lanjut diinterpretasikan dan disimpulkan menjadi data yang mudah dipahami. Dalam penelitian tentang pembelajaran bahasa arab dengan metode Al-'Arabiyah Baina Yadaika di ma'had Ali Bin Abi Tholib Universitas Muhammadiyah Yogyakarta ini, data yang diperoleh dari mahasiswa melalui angket masih berupa huruf, kemudian diukur dengan skala Likert, yaitu dengan skala 4 dimana huruf dirubah menjadi skor dengan ketentuan ;

a. Jawaban a dengan skor 4

b. Jawaban b dengan skor 3

c. Jawaban c dengan skor 2

d. Jawaban d dengan skor 1

Hasil tersebut masing-masing jumlah nilai dipresentasi untuk mengambil kesimpulan, dalam hal ini penulis mengkategorikan hasil dari nilai siswa menjadi tiga kategori yaitu sangat baik, baik dan kurang baik. Dalam 193.

72 Sutrisno Hadi, Metodologi Research II, ( Yogyakarta : Andi Offset,1990 ). hlm.

140 Jurnal Komunikasi dan Pendidikan Islam, Volume 1, Nomor 1, Juni 2018 
menentukan kategori, penulis menggunakan rumus interval dan tabel nilai yang akan penulis jelaskan dalam bab berikutnya.

Metode analisis yang digunakan penulis adalah metode analisis kualitatif dan analisis kuantitatif. Metode analisis diskriptif kualitatif, yang menggunakan analisis deskriptif nonstatistik dengan penjelasan, sebagai berikut :

a. Analisis Data Kualitatif

Analisis data kualitatif digunakan untuk menganalisis data yang berkaitan dengan keterangan seperti wawancara, observasi, dan bersifat interpretatif.

b. Analisis Data Kuantitatif

Analisisdatakuantitatifdigunakanuntukmenganalisi sdatayangberasaldariangketdanbersifatkuantitatifdianalis isdengan statistic rerata(mean),memakairumusberikut :

$$
\mathrm{P}=\frac{F}{N} \times 100 \%
$$

Keterangan:

$\mathrm{P} \quad$ : Angka persentase yang dicari

$\mathrm{F} \quad$ : Frekuensi

$\mathrm{N}$ : Number of Case (jumlah individu) ${ }^{73}$ hlm. 40 .

73 Anas Sudijono, Pengantar Statistik Pendidikan, (Jakarta: Rajawali Pers, 2005), 
Aziz Abdullah dan Purwoko : Pembelajaran Bahasa Arab Dengan Metode Al-'Arabiya Baina Yadaika Di Ma'had Ali Bin Abi Thalib Universitas Muhammadiyah Yogyakarta

\section{E. Pembelajaran Bahasa Arab}

1. Pengertian Pembelajaran Bahasa Arab

Pengertian pembelajaran adalah suatu upaya membelajarkan siswa untuk belajar yang mana guru bertindak sebagai fasilitator untuk membelajarkan siswa. Menurut Oemmar Hamalik, pembelajaran adalah suatu komunikasi yang tersusun meliputi unsur manusiawi, material, fasilitas, perlengkapan dan prosedur yang saling mempengaruhi untuk mencapai tujuan pembelajaran, dalam hal ini manusia terlibat dalam sistem pengajaran terdiri dari siswa, guru dan tenaga lainnya. ${ }^{74}$

Menurut Nana Sudjana bahwa pembelajaran adalah sebagai setiap upaya yang sistematis dan disengaja oleh pendidik untuk menciptakan kondisi-kondisi agar peserta didik melakukan kegiatan membelajarkan. Dalam pembelajaran terjadi interaksi antara guru dan siswa, disatu sisi guru melakukan sebuah aktivitas yang membawa anak kearah tujuan, lebih dari itu anak atau siswa dapat melakukan serangkaian kegiatan yang telah direncanakan oleh guru yaitu kegiatan belajar yang terarah pada tujuan yang ingin dicapai.

Bahasa Arab adalah bahasa yang digunakan oleh Allah untuk menurunkan Al-Qur'an, sehingga bahasa arab memiliki keistimewaan dari bahasa-bahasa lainnya.Bahasa

74Oemmar Hamalik, Belajar Mengajar, (Jakarta : PT. Bumi Aksara, 2008). hlm. 
Aziz Abdullah dan Purwoko : Pembelajaran Bahasa Arab Dengan Metode Al-'Arabiya Baina Yadaika Di Ma'had Ali Bin Abi Thalib Universitas Muhammadiyah Yogyakarta

arab adalah kalimat-kalimat yang digunakan bangsa Arab dalam mengutarakan maksud, perasaan maupun pikiran mereka. ${ }^{75}$

Pembelajaran bahasa Arab dapat didefinisikan suatu upaya membelajarkan siswa untuk belajar bahasa Arab dengan guru sebagai fasilitator dengan mengorganisasikan berbagai unsur untuk memperoleh tujuan yang ingin dicapai. Dalam pembelajaran bahasa Arab hendaknya mengacu pada upaya membina dan mengembangkan keempat segi kemampuan bahasa, yaitu : kemampuan menyimak (istima'), berbicara (takallam), membaca (qiro'ah), dan menulis (kitabah), agar mampu memahami bahasa, baik melalui pendengaran maupun tulisan (reseptif), dan mampu mengutarakan pikiran dan perasaan baik secara tulisan. ${ }^{76}$

2. Keistimewaan Bahasa Arab dan Kedudukanya

Keistimewaan Bahasa Arab adalah bahasa wahyu dari Allah Ta'ala, didalam al-Qur'an disebutkan bahasa Arab sebagai bahasa wahyu di beberapa ayat di antaranya; (QS. al-Zukhruf: 3, Yusuf: 2, Fussilat: 3 \& 44, al-Syura: 7, alAhqaf: 12, al-Ra'd: 37, al-Nahl: 103, Taha: 113, al-Syu'ara: 192-195 dan al-Zumar: 27-28).

${ }^{75}$ Musthafa Al-Ghulayani, Jami' Ad-Durus Al-'Arobiyah, (Semarang : CV. AsySyifa', 1991 ). hlm. 13.

${ }^{76}$ Acep Hermawan, Metodologi Pembelajaran Bahasa Arab,(Bandung : PT Remaja Rosdakarya, 2011 ). hlm. 130. 
Aziz Abdullah dan Purwoko : Pembelajaran Bahasa Arab Dengan Metode Al-'Arabiya Baina Yadaika Di Ma'had Ali Bin Abi Thalib Universitas Muhammadiyah Yogyakarta

Bahasa Arab adalah bahasa al-Qur'an, bukan hanya sekedar bahasa bangsa tertentu, bahasa Arab adalah bahasa umat islam, maka sudah menjadi sebuah keharusan bagi umat islam untuk mempelajarinya dan mempunyai rasa memiliki dan kepedulian terhadap bahasa Arab, karena kalau bukan kita umat islam, siapa lagi yang mau peduli.

3. Proses Pembelajaran bahasa arab

Belajar bahasa arab diartikan belajar agama karena Islam disampaikan dalam bahasa arab atau belajar bahasa Arab berarti belajar tentang Islam. Sebagaimana Allah Ta'ala berfirman didalam Al-Qur'an (Q.S.Yusuf 2)

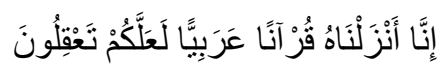

“Sesungguhnya Kami menurunkannya berupa Qur'an berbahasa Arab, agar kamu mengerti."77

Pembelajaran bahasa Arab seharusnya mengembangkan ketrampilan berkomunikasi baik secara lisan maupun tulisan, secara reseptif dan ekspresif untuk memahami, dan mengungkapkan informasi, perasaan serta pengembangan ilmu pengetahuan agama dan umum. Pengusaan empat skill merupakan target setiap pembelajaran bahasa termasuk bahasa Arab. Untuk mencapai target tersebut diperlukan strategi belajar yang tepat sehingga tujuan belajar sesuai dengan apa yang

77 Kementrian Agama RI,Al-Qur'an Tajwid dan Terjemahnya Dilengkapi dengan Asbabun Nuzul dan Hadits Shahih, (Bogor : PT. Sygma Examedia Arkanlema,2007), hlm. 235.

144 Jurnal Komunikasi dan Pendidikan Islam, Volume 1, Nomor 1, Juni 2018 
diharapkan.Keempat skill tersebut adalah sebagai berikut :78 mendengarkan, berbicara, membaca dan menulis.

a. Maharatul Istima' (mendengarkan)

Pada awal proses belajar seorang peserta didik hendaknya memahami aspek bunyi dari bahasa tersebut. Dengan bunyi bahasa itu menjadi sempurna dan dimengerti oleh lawan bicaranya. Atas dasar tersebut dikatakan bahwa belajar bahasa adalah mengenal bunyi huruf dengan benar dan kemudian mengenal bunyi tiap kata.

Abdul Majid menjelaskan bahwa tujuan dari pembelajaran istima' yaitu menirukan, menghafal, merangkum pokok-pokok pikiran dan memahami isinya. ${ }^{79}$ Pada fase ini peran seorang pendidik menjadi sangat penting karena diperlukan ketelatenan dalam melatih peserta didik melafalkan bunyi-bunyi dalam bahasa Arab. Al-tamtsil al-istima'iy adalah pola yang sangat bagus untuk membetulkan dialek dan bunyi yang keluar dari mulut dengan cara mengulang-ulang sebuah kata hingga terbentuk bunyi yang semestinya.

b. Maharatul Kalam (berbicara)

Berbicara dalam hal ini adalah kemampuan seseorang menggunakan bahasa yang dipelajari sebagai

78 Acep Hermawan, Op. Cit. hlm. 129. hlm. 69 .

${ }^{79}$ Abdul Majid, Pembelajaran bahasa, (Bandung : PT. Remaja Rosdakarya,1981). 
Aziz Abdullah dan Purwoko : Pembelajaran Bahasa Arab Dengan Metode Al-'Arabiya Baina Yadaika Di Ma'had Ali Bin Abi Thalib Universitas Muhammadiyah Yogyakarta

alat komunikasi. Kebiasaan seseorang yang selama ini tidak atau enggan melakukan komunikasi dengan native harus diubah dengan melakukan ihtikak (bersentuhan) langsung dengan native di sekitarnya yang mampu melakukan komunikasi.

Berbicara dengan lancar membutuhkan pembiasaan dan pemberanian, oleh karena itu diperlukan muhawalah wa al-khata' (trial and error), berbicara berulangulang untuk menuju kemampuan berbicara yang benar. Dengan memikirkan apa yang hendak disampaikan, membahas materi pembicaraan dan menentukan cara yang menyampaikan agar sesuai dengan makna yang diinginkan. 80

c. Maharatul Qira'ah (membaca)

Membaca pada dasarnya adalah beberapa aspek bahasa dari melafalkan bunyi, kosa kata, kaidah dan memahami kandungan teks. Belajar qira'ah berarti juga belajar aspek bahasa tersebut, sehingga dikatakan membaca bersifat aplikasi yang memadukan berbagai aspek ilmu bahasa untuk memahami isi teks.

Perkembangannya membaca bahasa Arab tidak sebatas membunyikan kata dengan kaidah nahwu atau sharf yang benar, tetapi juga mengarah pada pengambilan dan skill membaca dengan pemahaman makna yang

80 Imam Makhruf.Op.Cit.hlm.149

146 Jurnal Komunikasi dan Pendidikan Islam, Volume 1, Nomor 1, Juni 2018 
benar. Untuk itu harus memperhatikan hal-hal berikut ini, yaitu: memperhatikan struktur, memperhatikan makna, dan kemudian mengambil kesimpulan.

d. Maharatul Kitabah (menulis)

Kegiatan ini seseorang perlu melakukan rabth sebagaimana dengan qira'ah. Hanya saja kitabah lebih membutuhkan perhatian dan ketelitian karena semua kata dan struktur berasal dari penulis. Setiap menulis harus dipikirkan struktur kalimatnya, makna yang diharapkan dan uslub yang dipakai. Hal itu dilakukan karena kitabah dalam studi bahasa Arab menduduki maharah yang sangat sulit. Sehingga memerlukan latihan dan strategi yang baik, agar dapat dipahami oleh pembaca.

Semua aspek di atas hal terpenting adalah menciptakan lingkungan bahasa yang menunjang proses belajar peserta didik sehingga terciptalah situasi belajar dalam segala kondisi. Jadi bukan hanya dalam proses belajar tapi juga dalam percakapan keseharian. Pembiasaan mendengarkan dan menonton contoh-contoh percakapan menjadi penting dalam proses ini. Sehingga terciptalah bi'ah arabiyyah.

4. Tujuan Pembelajaran Bahasa Arab

Pembelajaran bahasa arab bertujuan untuk menguasai empat keterampilan bahasa, yaitu keterampilan 
Aziz Abdullah dan Purwoko : Pembelajaran Bahasa Arab Dengan Metode Al-'Arabiya Baina Yadaika Di Ma'had Ali Bin Abi Thalib Universitas Muhammadiyah Yogyakarta

mendengar (istima), ketrampilan berbicara (kalam), keterampilan membaca (qiro`ah), keterampilan menulis (kitabah).

Keterampilan-keterampilan tersebut mahasiswa diharapkan mempraktekkannya dalam kehidupannya sehari-hari,mahasiswa dapat mendengarkan dan menyimak dengan seksama apa yang dibaca oleh guru, sehingga hasil sesuai dengan yang di harapkan, mahasiswa dapat berbicara bahaasa arab dengan baik sesuai ketentuan dan kaidahkaidah bahasa arab yang telah diajarkan, mahasiswa dapat mempraktikkan bahasa arabnya dalam memahami dan mempelajari kitab-kitab arab, seperti yang sering kita dengar dengan sebutan kitab kuning atau kitab gundul.

Dari prinsip-prinsip pembelajaran bahasa asing yang disebutkan Kamal Ibrahim badri yang meliputi; ucapan sebelum tulisan, kalimat yang mendasar, kaidah bunyi, bahasa yang bermakna. ${ }^{81}$ Maka terkandung didalamnya halhal berikut:

a. Jenjang Pengajaran Mufrodat(kosa kata)

Pengajaran kosa kata hendaknya mempertimbangkan dari aspek penggunaannya bagi peserta didik, yaitu diawali dengan memberikan materi kosa kata yang banyak digunakan dalam keseharian dan berupa kata dasar. Selanjutnya memberikan materi kata sambung. Hal

81 Imam Makhruf. Op. Cit. hlm.47. 
ini dilakukan agar peserta didik dapat menyusun kalimat sempurna sehingga terus bertambah dan berkembang kemampuannya.

b. Jenjang Pengajaran Qowaid (Morfem)

Dalam pengajaran Qowaid, baik Qowaid Nahwu maupun Qowaid Sharaf juga harus mempertimbangkan kegunaannya dalam percakapan/keseharian. Dalam pengajaran Qawaid Nahwu misalnya, harus diawali dengan materi tentang kalimat sempurna (Jumlah Mufiidah), namun rincian materi penyajian harus dengan cara mengajarkan tentang isim, fi'il, dan huruf.

c. Tahapan pengajaran makna (دلالة المعانى)

Mengajarkan makna kalimat atau kata-kata, seorang guru bahasa Arab hendaknya memulainya dengan memilih kata-kata/kalimat yang paling banyak digunakan/ditemuidalam keseharian meraka.Selanjutnya makna kalimat lugas sebelum makna kalimat yang mengandung arti idiomatic.

Secara sederhana, metode pengajaran bahasa Arab dapat digolongkan menjadi dua macam, yaitu: metode tradisional/klasikal dan metode modern. ${ }^{82}$

82Ibid. hlm 2 
Aziz Abdullah dan Purwoko : Pembelajaran Bahasa Arab Dengan Metode Al-'Arabiya Baina Yadaika Di Ma'had Ali Bin Abi Thalib Universitas Muhammadiyah Yogyakarta

a. Metode pengajaran bahasa Arab tradisional

Adalah metode pengajaran bahasa Arab yang terfokus pada "bahasa sebagai budaya ilmu" sehingga belajar bahasa Arab berarti belajar secara mendalam tentang seluk-beluk ilmu bahasa Arab, baik aspek gramatika/sintaksis (Qowaid nahwu), morfem/morfologi (Qowaid as-sharf) ataupun sastra (adab).

Metode yang berkembang dan masyhur digunakan untuk tujuan tersebut adalah Metode qowaid dan tarjamah. Metode tersebut mampu bertahan beberapa abad, bahkan sampai sekarang pesantren-pesantren di Indonesia, khususnya pesantren salafiyah masih menerapkan metode tersebut. Hal ini didasarkan pada hal-hal sebagai berikut:

1) Tujuan pengajaran bahasa arab tampaknya pada aspek budaya/ilmu, terutama nahwu dan ilmu sharaf.

2) Kemampuan ilmu nahwu dianggap sebagai syarat mutlak sebagai alat untuk memahami teks/kata bahasa Arab klasik yang tidak memakai harakat, dan tanda baca lainnya.

3) Bidang tersebut merupakan tradisi turun temurun, sehingga kemampuan di bidang itu memberikan "rasa percaya diri (gengsi) tersendiri di kalangan mereka". 
b. Metode pengajaran bahasa Arab modern

Adalah metode pengajaran yang berorientasi pada tujuan bahasa sebagai alat. Artinya, bahasa Arab dipandang sebagai alat komunikasi dalam kehidupan modern, sehingga inti belajar bahasa Arab adalah kemampuan untuk menggunakan bahasa tersebut secara aktif dan mampu memahami ucapan/ungkapan dalam bahasa Arab.

Metode yang lazim digunakan dalam pengajarannya adalah metode langsung (tariigah al mubasysyarah). Munculnya metode ini didasari pada asumsi bahwa bahasa adalah sesuatu yang hidup, oleh karena itu harus dikomunikasikan dan dilatih terus sebagaimana anak kecil belajar bahasa. Lebih jelasnya dengan contoh sebagai berikut:

1) Metode Qowa'id dan tarjamah (Tariiqatul al Qowaid Wa Tarjamah)

Penerapan metode ini lebih cocok jika tujuan pengajaran bahasa Arab adalah sebagai kebudayaan, yaitu untuk mengetahui nilai sastra yang tinggi dan untuk memiliki kemampuan kognitif yang terlatih dalam menghafal teks-teks serta memahami apa yang 
Aziz Abdullah dan Purwoko : Pembelajaran Bahasa Arab Dengan Metode Al-'Arabiya Baina Yadaika Di Ma'had Ali Bin Abi Thalib Universitas Muhammadiyah Yogyakarta

terkandung di dalam tulisan-tulisan atau buku-buku teks, terutama buku Arab klasik. 83

2) Metode langsung (at Thariiqatu al Mubaasyarah)

Penekanan pada metode ini adalah pada latihan percakapan terus-menerus antara guru dan peserta didik dengan menggunakan bahasa Arab tanpa sedikitpun menggunakan bahasa ibu, baik dalam menjelaskan makna kosa kata maupun menerjemah, (dalam hal ini dibutuhkan sebuah media). Perlu menjadi bahan revisi disini adalah bahwa dalam metode langsung, bahasa Arab menjadi bahasa pengantar dalam pengajaran dengan menekankan pada aspek penuturan yang benar (al - Nutqu al Shahiih) ${ }^{84}$

\section{F. MetodeAl-'Arabiyah Baina Yadaika}

1. Pengertian Metode Al-'Arabiyah Baina Yadaika

Metode Al-'Arabiyah Baina Yadaika secara bahasa diartikan bahasa arab diantara kedua tanganmu, yang bermakna kamu telah menguasainya. Dalam hal ini metode Al-'Arabiyah Baina Yadaikaadalah suatu metode yang menstimulasikan belajar bahasa arab secara langsung dan

\footnotetext{
${ }^{83}$ Abdul Hamid, Uril Baharudin, Bisri Mustofa, Metode Pengajaran Bahasa Arab, (UIN Malang Press 2008). hlm. 18.

84 Abdul Hamid, Uril Baharudin, Bisri Musthofa, Metode Pengajaran Bahasa Arab, (UIN Malang Press 2008). hlm. 23
}

152 Jurnal Komunikasi dan Pendidikan Islam, Volume 1, Nomor 1, Juni 2018 
Aziz Abdullah dan Purwoko : Pembelajaran Bahasa Arab Dengan Metode Al-'Arabiya Baina Yadaika Di Ma'had Ali Bin Abi Thalib Universitas Muhammadiyah Yogyakarta

intensif dalam berkomunikasi, dengan memanfaatkan teknologi modern dengan tahapan-tahapan yang harus dilalui.Metode $A l$ 'Arabiyah Baina Yadaika adalah salah satu metode pembelajaran Bahasa Arab yang bersumber dari sebuah buku panduan program belajar Bahasa Arab untuk segala tingkatan yang disusun berdasarkan penelitian mendalam tentang pengajaran Bahasa Arab, disusun oleh pakar Bahasa Arab yang sangat kompeten dibidangnya. ${ }^{85}$

Buku ajar bahasaarab ini dikarang oleh tim pengarang yaitu: Abdurrahman bin Ibrahim al-Fauzan, Mukhtar al-Thahir Husain, dan Muhammad abdul Khaliq Muhammad Fadhl yang di dampingi oleh Muhamman bin Abdurrahman Ali al-Syaekh. Buku ini diterbitkan oleh Muassasah al-Waqf al-Islami Riyadh Saudi Arabia pada tahun 2002 M (1424 H) untuk cetakan pertamanya, yang sengaja dibuat untuk pembelajarab bahasa Arab bagi non Arab (ta'lim al-Arabiyah li ghairi al-natiqina biha).

2. Ciri-Ciri Umum Metode Al-'Arabiyah Baina Yadaika

Metode Al-'Arabiyah Baina Yadaik turut ikut andil dan berkontribusi dalam bidang pendidikan bahasa arab. Maka munculah metode Al-'Arabiyah Baina Yadaik memiliki ciri-ciri umum sebagai berikut: 86

${ }^{85}$ Abdurrahman bin Ibrahim Al-Fauzan, Buku Panduan Belajar Bahasa Arab 'Al 'Arabiyah Baina Yadaik,( Jakarta : PT. Future Media Gate FMG, 2002 ). hlm.3

${ }^{86}$ Abdurrahman bin Ibrahim Al-Fauzan, Al 'Arabiyah Baina Yadaik Kitaabut Thoolib), (Riyadh : Maktabah Al-Malik Fahd, 2007). hlm.ذ. 
Aziz Abdullah dan Purwoko : Pembelajaran Bahasa Arab Dengan Metode Al-'Arabiya Baina Yadaika Di Ma'had Ali Bin Abi Thalib Universitas Muhammadiyah Yogyakarta

a. Metode inibertujuan membuat seorang pelajar menguasai kemampuanbahasa, kemampuan komunikasi, dan kemampuan budaya.

1) Kemampuan bahasa, mencakup:

a) Keahlian berbahasa, yang terdiri dari 4 hal yaitu:

(1) Mendengar

(2) Berbicara

(3) Membaca

(4) Menulis

b) Unsur-unsur bahasa, yang terdiri dari tiga hal yaitu: Sistem suara, mufradat dan susunan kata bahasa (disertai keterangan tentang kaidah-kaidah Nahwu, Sharaf, dan Imla' atau penulisan kata).

2) Kemampuan komunikasi

Tujuannnya adalah menuntun para pelajar agar mampu berkomunikasi dengan bahasa Arab dan berinteraksi secara lisan dan tulisan, serta mampu menyusun kalimat dan ungkapan.

3) Kemampuan budaya

Para pelajar diperkenalkan dengan berbagai sisi kebudayaan bahasa Arab. Selain itu, ditambahkan pula berbagai bentuk kebudayaan bahasa Arab dan bentuk kebudayaan umum yang tidak bertentangan dengan prinsip-prinsip Islam. 
b. Para pengguna Metode Al-'Arabiyah Baina Yadaika

Metode ini ditujukan untuk para pelajar remaja dan dewasa baik mereka terikat dalam satu lembaga pendidikan atau belajar otodidak, baik melalui program pembelajaran yang intensif ataupun non-intensif.Selain itu, metode ini ditujukan kepada para pelajar yang belum pernah mengenal bahasa Arab.

Buku ini membimbing para pelajar mulai dari nol hingga menguasai bahasa Arab dan mampu berkomunikasi dengan para pengguna bahasa Arab baik secara lisan dan tulisa. Hal ini memungkinkan bagi mereka untuk melanjutkan pendidikan ke universitasuniversitas yang menggunakan bahasa Arab sebagai bahasa pengantar.

c. Bahasa yang digunakan oleh Metode ABY

Metode ABY ini menggunakan bahasa Arab yang fashih (baku), tidak menggunakan bahasa amiyah (pasaran), dan tidak juga menggunakan bahasa perantara sebagai cara yang ideal dalam pengajaran bahasa.

d. Kandungan Metode ABY

Silsilah ini terbagi dalam tiga tingkatan pembelajaran yaitu tingkat dasar, tingkat menengah, dan tingkat lanjut. Untuk masing-masing tingkatan tersedia satu kitab untuk pelajar dan kitab untuk guru. Selain itu, tersedia juga kamus yang memuat lebih dari 7000 
Aziz Abdullah dan Purwoko : Pembelajaran Bahasa Arab Dengan Metode Al-'Arabiya Baina Yadaika Di Ma'had Ali Bin Abi Thalib Universitas Muhammadiyah Yogyakarta

kosakata pokok. Silsilah ini juga dilengkapi dengan panduan audio.

3. Penyusunan Metode ABY

Metode ABY menggunakan metode pembelajaran yang modern sebagaimana metode pembelajaran ilmu bahasa-bahasa asing (terutama bahasa Inggris dan Prancis) dengan tetap memperhatikan karakteristikkhusus bahasa Arab. Hal-hal yang diperhatikan dalam penyusunan metode ini adalah sebagai berikut:

a. Keterpaduan antara keahlian berbahasa dan unsurunsurnya.

b. Memberikan perhatian pada sistem suara dalam bahasa Arab.

c. Memperhatikan proses tadarruj (bertahap) dalam menyampaikan materi pelajaran.

d. Memperhatikan perbedaan-perbedaan individu di antara para pelajar.

e. Menyertakan latihan-latihan yang beragam.

f. Kesesuaian kandungan dengan tingkatan pelajar.

g. Menggunakan sistem unit-pelajaran dalam menyampaikan materi.

h. Menampilkan setiap kosakata dalam susunan yang sempurna.

i. Memperhatikan kemampuan pengucapan pada tingkat lanjut. 
j. Menyertakan daftar kosakata yang terdapat dalam setiap kitab.

k. Menyertakan latihan berkala dalam setiap kitab.

1. Memanfaatkan berbagai pengalaman khusus dalam menyusun materi-materi pelajaran bahasa Arab dan bahasa-bahasa lain.

m. Menampilkan nilai-nilai budaya dengan cara yang menarik.

n. Menggunakan banyak gambar, khususnya dalam buku pertama yang mengandung lebih dari 1000 gambar penjelas.

4. Waktu Pembelajaran Metode ABY

Waktu standar untuk menyampaikan seluruh pelajaran dalam kitab-kitab Silsilah ini kurang lebih 300 jam pelajaran (satu jam pelajaran sekitar 45 menit). Ini berarti 100 jam pelajaran untuk setiap tingkatan. Jika materi pelajaran Silsilah ini disampaikan dalam program yang tidak intensif, maka dibutuhkan waktu 3 tahun. Jika disampaikan dengan program intensif maka tergantung jumlah jam pelajaran setiap minggunya.

5. Keistimewaan Metode ABY

Metode Al-Arabiyah Baina Yadaika sudah teruji untuk pengajaran Bahasa Arab di penjuru dunia karena memiliki 
Aziz Abdullah dan Purwoko : Pembelajaran Bahasa Arab Dengan Metode Al-'Arabiya Baina Yadaika Di Ma'had Ali Bin Abi Thalib Universitas Muhammadiyah Yogyakarta

kelebihan dan keistimewaan sebagai berikut:87

a. Mengenalkan teori modern dalam pengajaran Bahasa Arab

b. Menggunakan metode yang mudah dan bertahap

c. Mengaplikasikan kemampuan dalam berbahasa: pendengaran, ucapan, membaca dan menulis

d. Memberikan ujian pilihan sesuai dengan tingkatan

e. Dilengkapi dengan materi-materi pendukung yang membantu program pembelajaran

f. Sesuai untuk segala tingkatan (sekolah dasar, menengah, perguruan tinggi) baik muda ataupun orang tua yang ingin cepat menguasai.

\section{G. Sajian dan Analisis Data}

1. Pembelajaran Bahasa Arab dengan Metode Al-'Arobiyah Baina Yadaika

a. Pembelajaran Bahasa Arab dengan Metode Al-'Arobiyah Baina Yadaika.

Pembelajaran bahasa arab dengan metode $\mathrm{Al}$ 'Arobiyah Baina Yadaika di Mustawa Tamhidy Ma'had Ali Bin Abi Tholib adalah untuk pemula, yang belum bisa berbahasa arab, pembelajarannya dibagi dua kelompok

${ }^{87}$ Abdurrahman bin Ibrahim Al-Fauzan, Buku Panduan Belajar Bahasa Arab 'Al 'Arabiyah Baina Yadaik,( Jakarta : PT. Future Media Gate FMG, 2002 ). hlm.3

158 Jurnal Komunikasi dan Pendidikan Islam, Volume 1, Nomor 1, Juni 2018 
Aziz Abdullah dan Purwoko : Pembelajaran Bahasa Arab Dengan Metode Al-'Arabiya

Baina Yadaika Di Ma'had Ali Bin Abi Thalib Universitas Muhammadiyah Yogyakarta

yaitu kelompok khiwar (muhadatsah) dan kelompok tadribat. 88

Pembelajaran bahasa arab dengan metode $A l$ 'Arobiyah Baina Yadaika di Mustawa Tamhidy Ma'had Ali Bin Abi Tholib adalah dengan menguasai empat kemampuan bahasa yaitu :89

1) Kemampuan mendengarkan/menyimak (sima'ah)

2) Kemampuan membaca (qiroah)

3) Kemampuan berbicara (kalam)

4) Kemampuan menulis (kitabah)

b. TujuanPembelajaran Bahasa Arab dengan Metode Al'Arobiyah Baina Yadaika.

Tujuan pembelajaran bahasa arab dengan metode Al-'Arobiyah Baina Yadaika di Mustawa Tamhidy Ma'had Ali Bin Abi Tholib adalah untuk menguasai empat kemampuan bahasa yaitu maharotul istima, maharotul qiroah,maharotul kalam dan maharotul kitabah", minimal mengenal bahasa arab dari yang termudah lebih dulu, yang mudah-mudah dulu. ${ }^{90}$

Keterampilan-keterampilan tersebut mahasiswa diharapkan mempraktekkannya dalam kehidupannya November 2015

${ }^{88}$ Hasil Wawancara dengan Ustadz Fahri Imanul Haq Lc, M.Si tanggal 23 ${ }^{89}$ Hasil Wawancara dengan Ustadz Muhammad Iqbal Lc, tanggal 26 Oktober 2015 2015

${ }^{90}$ Hasil Wawancara dengan Ustadz Fahri Imanul Haq Lc, tanggal 26 Oktober 
Aziz Abdullah dan Purwoko : Pembelajaran Bahasa Arab Dengan Metode Al-'Arabiya Baina Yadaika Di Ma'had Ali Bin Abi Thalib Universitas Muhammadiyah Yogyakarta

sehari-hari, mahasiswa dapat mendengarkan dan menyimak dengan seksama apa yang dibaca oleh guru, sehingga hasil sesuai dengan yang diharapkan, mahasiswa dapat berbicara bahasa arab dengan baik sesuai ketentuan dan kaidah-kaidah bahasa arab yang telah diajarkan, siswa dapat mempraktikkan bahasa arabnya dalam memahami dan mempelajari kitab-kitab arab, seperti yang sering kita dengar dengan sebutan kitab kuning atau kitab gundul.

Mahasiswa dapat memahami isi kandungan Alquran kemudian mendakwahkannya kepada masyarakat umum, mahasiswa dapat menulis tulisan dengan baik sesuai kaedah tulisan yang telah ada, baik berupa tulisan biasa maupun dalam berbagai variasi khot atau kaligrafi. Dan yang paling penting adalah mahasiswa dapat membaca tulisan arab dengan benar sesuai kaedah tajwid atau kaedah makhorijul huruf, sehingga dapat melantunkan ayat-ayat Al-Qur'an dengan benar dan tepat. Inilah poin-poin penting yang diharapkan dalam pembelajaran bahasa arab. Jadi sangat dianjurkan kita mempelajari kemudian mendemonstrasikan dan mengajarkan bahasa arab kepada segenap umat islam..$^{91}$ 
c. Proses Pembelajaran Bahasa Arab dengan Metode Al'Arobiyah Baina Yadaika.

Proses pembelajaran bahasa arab dengan metode Al-'Arobiyah Baina Yadaika di Mustawa Tamhidy Ma'had Ali Bin Abi Tholib menyiapkan latihan-latihan khiwar yang bervariasi dan tidak monoton, dan mahasiswa menulis di buku tadribat. Untuk khiwar didesain dengan menyiapkan cara pembelajaran bahasa arab dengan metode Al-'Arobiyah Baina Yadaikayaitu sebagai berikut :92

1) Mahasiswa menutup buku, ustadz membaca dan mahasiswa mendengarkan.

2) Mahasiswa menutup buku, ustadz membaca dan mahasiswa menirukan.

3) Mahasiswa membuka buku, ustadz membaca dan mahasiswa menirukan dengan membaca.

4) Ustadz membagi mahasiswa menjadi beberapa kelompok, dan bergantian membaca.

5) Ustadz menjelaskan mufradat dan makna sesuai materi yang ada.

6) Mahasiswa menghafal dan mempratekkan didepan kelas dan ustadz menilai.

7) Memberikan latihan (tadribat) sesuai materi. 
Aziz Abdullah dan Purwoko : Pembelajaran Bahasa Arab Dengan Metode Al-'Arabiya Baina Yadaika Di Ma'had Ali Bin Abi Thalib Universitas Muhammadiyah Yogyakarta

d. Strategi Ustadz untuk menarik perhatian mahasiswa dalam pembelajaran bahasa arab metodeAl-'Arobiyah Baina Yadaika.

Strategi Ustadz untuk menarik perhatian mahasiswa dalam pembelajaran bahasa arab dengan metode yang tidak monoton, yaitu membaca, mufrodat, praktek khiwar. Selain itu bisa dengan selingan materi seperti cerita atau kisah yang menarik supaya suasana kelas tidak monoton, selingan kisah-kisah humor, materi dan teori yang menarik dan mudah dipahami mahasiswa. ${ }^{93}$

e. Cara Ustadz mengetahui kemampuan masing-masing mahasiswa dalam pembelajaran bahasa arab dengan metode Al-'Arobiyah Baina Yadaika.

Untuk mengetahui kemampuan masing-masing mahasiswa dalam pembelajaran bahasa arab yaitu dengan melihat kemampuan mahasiswa ketika maju didepan kelas, hafalannya, sering tidaknya dia maju mempratekan khiwar. Dan dengan melihat jawaban dari tadribat yang dikerjakan mahasiswa, melihat keaktifan mahasiswa, aktif bertanya dan aktif menjawab soal latihan/ tadribat. ${ }^{94}$

${ }^{93}$ Hasil Wawancara dengan Ustadz Muhammad Iqbal Lc, tanggal 26 Oktober ${ }^{94}$ Hasil Wawancara dengan Ustadz Fahri Imanul Haq Lc, tanggal 26 Oktober 2015

162 Jurnal Komunikasi dan Pendidikan Islam, Volume 1, Nomor 1, Juni 2018 
Aziz Abdullah dan Purwoko : Pembelajaran Bahasa Arab Dengan Metode Al-'Arabiya Baina Yadaika Di Ma'had Ali Bin Abi Thalib Universitas Muhammadiyah Yogyakarta

f. Metode yang Ustadz lakukan dalam pembelajaran bahasa arab dengan metode Al-'Arobiyah Baina Yadaika.

Metode yang Ustadz lakukan dalam pembelajaran bahasa arab dengan metode Al-'Arobiyah Baina Yadaika di Mustawa Tamhidy Ma'had Ali Bin Abi Tholib dengan kemahiran khiwar, banyak latihan khiwar. Selain itu dengan memperbanyak latihan tadribat dalam kitab tersebut, mahasiswa menjawab secara bergantian, ustadz membahas mufradat dan materi tersebut. ${ }^{95}$

g. Media yang Ustadz pergunakan dalam pembelajaran bahasa arab dengan metode Al-'Arobiyah Baina Yadaika.

Media yang Ustadz pergunakan dalam pembelajaran bahasa arab dengan metodeAl-'Arobiyah Baina Yadaika di Mustawa Tamhidy Ma'had Ali Bin Abi Tholib dengan laptop, audio visual, proyektor, LCD, TV dan lain-lain. Contohnya media yang dipergunakan dalam pembelajaran bahasa arab dengan audio dan video dan tambahan materi video "Thoriq" .96

h. Materi yang ustadz gunakan dalam pembelajaran bahasa arab dengan metode Al-'Arobiyah Baina Yadaika.

Materi bahasa arab yang ustadz gunakan dalam pembelajaran bahasa arab dengan metode Al-'Arobiyah

${ }^{95}$ Hasil Wawancara dengan Ustadz Muhammad Iqbal Lc, tanggal 26 Oktober ${ }^{96}$ Hasil Wawancara dengan Ustadz Fahri Imanul Haq Lc, tanggal 26 Oktober 
Aziz Abdullah dan Purwoko : Pembelajaran Bahasa Arab Dengan Metode Al-'Arabiya Baina Yadaika Di Ma'had Ali Bin Abi Thalib Universitas Muhammadiyah Yogyakarta

Baina Yadaika di Mustawa Tamhidy Ma'had Ali Bin Abi Tholib untuk melatih keahlian berbahasa, yang terdiri dari 4 hal yaitu: mendengar, berbicara, membaca dan menulis.

Materi yang meliputi unsur-unsur bahasa, yang terdiri dari tiga hal yaitu: Sistem suara, mufradat dan susunan kata bahasa (disertai keterangan tentang kaidahkaidah Nahwu, Sharaf, dan Imla' atau penulisan kata. ${ }^{97}$

MateriABY ini menggunakan bahasa Arab yang fashih (baku), tidak menggunakan bahasa amiyah (pasaran), dan tidak juga menggunakan bahasa perantara sebagai cara yang ideal dalam pengajaran bahasa.

Materi bahasa arab yang ustadz gunakan dalam pembelajaran bahasa arab dengan metode Al-'Arobiyah Baina Yadaika di Mustawa Tamhidy Ma'had Ali Bin Abi Tholib selain buku ABY, kamus ABY, nahwu shorof dasar yang mudah-mudah dahulu.

Materi bahasa arab lain yang ustadz gunakan dalam pembelajaran bahasa arab di Ma'had banyak namun untuk mustawa tamhidy belum dikenalkan nahwu shorof, nanti dimustawa berikutnya seperti adab, balaghoh dan lain-lain. 
2. HasilPembelajaran Bahasa Arab Metode Al-'Arabiyah Baina Yadaika.

Penelitian tentang pembelajaran bahasa arab dengan metode Al-'Arabiyah Baina Yadaika di ma'had Ali Bin Abi Tholib Universitas Muhammadiyah Yogyakarta ini, data yang diperoleh dari mahasiswa melalui angket masih berupa huruf, huruf dirubah menjadi skor dengan ketentuan.

Untuk mengetahui hasil pembelajaran bahasa arab dengan metode Al-'Arobiyah Baina Yadaika di Mustawa Tamhidy Ma'had Ali Bin Abi Tholib dengan menggunakan angket. Jumlah pertanyaan angket untuk mahasiswa dalam pembelajaran bahasa arab dengan metode Al-'Arobiyah Baina Yadaika di Mustawa Tamhidy Ma'had Ali Bin Abi Tholib sebanyak 30 soal dengan 4 alternatif jawaban. Dengan menggunakan instrumen penelitian sebagai berikut : 
Aziz Abdullah dan Purwoko : Pembelajaran Bahasa Arab Dengan Metode Al-'Arabiya Baina Yadaika Di Ma'had Ali Bin Abi Thalib Universitas Muhammadiyah Yogyakarta

Tabel 5 :

Instrumen Penelitian Pembelajaran Bahasa Arab dengan Metode Al-Arabiyah Baina Yadaika di Ma'had Ali Bin Abi Thalib Universitas Muhammadiyah Yogyakarta

\begin{tabular}{|l|l|c|c|}
\hline No & Aspek Yang Dinilai & Jumlah & Nomer Item \\
\hline 1 & $\begin{array}{l}\text { Kemahiran menyimak } \\
(\text { fahmul masmu') }\end{array}$ & 4 & $1,2,3,4$ \\
\hline 2 & $\begin{array}{l}\text { Kemahiran berbicara } \\
(\text { muhadatsah })\end{array}$ & 4 & $5,6,7,8$ \\
\hline 3 & $\begin{array}{l}\text { Kemahiran membaca } \\
(\text { qira'ah })\end{array}$ & 4 & $9,10,11,12$ \\
\hline 4 & Kemahiran menulis (kitabah) & 4 & $13,14,15,16$ \\
\hline 5 & $\begin{array}{l}\text { Al-Arabiyah Baina Yadaika } \\
(\text { ABY) }\end{array}$ & 4 & $17,18,19,20$ \\
\hline 6 & $\begin{array}{l}\text { Persiapan dan pengulangan } \\
(\text { muraja'ah) }\end{array}$ & 2 & 21,22 \\
\hline 7 & Metode Pengajaran Dosen & 2 & 23,24 \\
\hline 8 & $\begin{array}{l}\text { Proses Pembelajaran di } \\
\text { Ma'had }\end{array}$ & 2 & 25,26 \\
\hline 9 & Praktek Bahasa Arab & 2 & 27,28 \\
\hline 10 & Motivasi belajar bahasa arab & 2 & 29,30 \\
\hline
\end{tabular}

Jumlah mahasiswa yang diteliti sebanyak 26 mahasiswa, yang kemudian akan diolah untuk mengetahui hasil pembelajaran bahasa arab dengan metode Al-'Arobiyah Baina Yadaika di Mustawa Tamhidy Ma'had Ali Bin Abi Tholib Universitas Muhammadiyah Yogyakarta tahun pelajaran 2015/2016 yang akan disajikan dalam tabel berikut ini :98

98 Hasil Angket pada tanggal 12 Oktober 2015 
Aziz Abdullah dan Purwoko : Pembelajaran Bahasa Arab Dengan Metode Al-'Arabiya Baina Yadaika Di Ma'had Ali Bin Abi Thalib Universitas Muhammadiyah Yogyakarta

Tabel 6 :

Jawaban Angket dan Nilai Responden

Pembelajaran Bahasa Arab Metode Al-'Arobiyah Baina Yadaika di Mustawa Tamhidy Ma'had Ali Bin Abi Thalib

\begin{tabular}{|c|c|c|c|c|c|c|c|c|c|}
\hline \multirow[t]{2}{*}{ No. } & \multicolumn{4}{|c|}{$\begin{array}{c}\text { FrekuensiAlternatif } \\
\text { Jawaban }\end{array}$} & \multicolumn{4}{|c|}{ Nilai } & \multirow[t]{2}{*}{ Jumlah } \\
\hline & A & B & C & D & A & B & C & D & \\
\hline 1. & 12 & 16 & 2 & 0 & 48 & 48 & 4 & 0 & 100 \\
\hline 2. & 6 & 18 & 6 & 0 & 24 & 54 & 12 & 0 & 90 \\
\hline 3. & 4 & 13 & 12 & 1 & 16 & 39 & 24 & 1 & 80 \\
\hline 4. & 15 & 10 & 5 & 0 & 60 & 30 & 10 & 0 & 100 \\
\hline 5. & 8 & 21 & 1 & 0 & 32 & 63 & 2 & 0 & 97 \\
\hline 6. & 8 & 14 & 6 & 2 & 32 & 42 & 12 & 2 & 88 \\
\hline 7. & 15 & 11 & 4 & 0 & 60 & 33 & 8 & 0 & 101 \\
\hline 8. & 6 & 20 & 4 & 0 & 24 & 60 & 8 & 0 & 92 \\
\hline 9. & 21 & 4 & 5 & 0 & 84 & 12 & 10 & 0 & 106 \\
\hline 10. & 3 & 27 & & 0 & 12 & 81 & 0 & 0 & 93 \\
\hline 11. & 26 & 2 & 2 & 0 & 104 & 6 & 4 & 0 & 114 \\
\hline 12. & 4 & 19 & 7 & 0 & 16 & 57 & 14 & 0 & 87 \\
\hline 13. & 5 & 20 & 1 & 4 & 20 & 60 & 2 & 4 & 86 \\
\hline 14. & 23 & 7 & & 0 & 92 & 21 & 0 & 0 & 113 \\
\hline 15. & 3 & 19 & 8 & 0 & 12 & 57 & 16 & 0 & 85 \\
\hline 16. & 2 & 23 & 3 & 2 & 8 & 69 & 6 & 2 & 85 \\
\hline 17. & 3 & 16 & 11 & 0 & 12 & 48 & 22 & 0 & 82 \\
\hline 18. & 7 & 20 & 3 & 0 & 28 & 60 & 6 & 0 & 94 \\
\hline 19. & 4 & 16 & 10 & 0 & 16 & 48 & 20 & 0 & 84 \\
\hline 20. & 9 & 16 & 2 & 3 & 36 & 48 & 4 & 3 & 91 \\
\hline 21. & 10 & 16 & 4 & 0 & 40 & 48 & 8 & 0 & 96 \\
\hline 22. & 2 & 21 & 7 & 0 & 8 & 63 & 14 & 0 & 85 \\
\hline 23. & 2 & 24 & 4 & 0 & 8 & 72 & 8 & 0 & 88 \\
\hline 24. & 4 & 21 & 5 & 0 & 16 & 63 & 10 & 0 & 89 \\
\hline 25. & 3 & 10 & 14 & 3 & 12 & 30 & 28 & 3 & 73 \\
\hline 26. & 5 & 18 & 6 & 1 & 20 & 54 & 12 & 1 & 87 \\
\hline & & & & & & Skor & rting & & 114 \\
\hline & & & & & & Skor & rend & & 73 \\
\hline & & & & & & Selisi & & & 41 \\
\hline & & & & & & Selisi & Inter & & 13,7 \\
\hline & & & & & & Dibu & kan & & 14 \\
\hline
\end{tabular}


Aziz Abdullah dan Purwoko : Pembelajaran Bahasa Arab Dengan Metode Al-'Arabiya Baina Yadaika Di Ma'had Ali Bin Abi Thalib Universitas Muhammadiyah Yogyakarta

Skor tabel diatas dibuat interval untuk menentukan kriteria sangat baik, baik atau kurang baik. Pada tabel diatas skor terendah adalah 73, sedang skor tertinggi adalah 114 . Sehingga dibuat 3 interval untuk mengukur hasilpembelajaran bahasa arab dengan metode Al-'Arobiyah Baina Yadaika di Mustawa Tamhidy Ma'had Ali Bin Abi Thalib, masing-masing interval selisih 41. Interval I :102 115 , interval II : 88 - 101 , dan interval III : 72 - 87. Selisih angka 41 berasal dari nilai tertinggi dikurangi nilai terendah dibagi $3 .{ }^{99}$

Tabel 7 :

Interval Skor Pembelajaran Bahasa Arab Metode Al'ArobiyahBaina Yadaika di Mustawa Tamhidy Ma'had Ali Bin Abi Thalib ${ }^{100}$

\begin{tabular}{|c|l|l|l|}
\hline No & Interval & Nilai & Jumlah \\
\hline I & $102-115$ & $106 ; 114 ; 113$ & 3 \\
\hline II & $88-101$ & $100 ; 90 ; 100 ; 97 ; 88 ;$ & \\
& & $101 ; 92 ; 93 ; 94 ; 91 ; 96$ & \\
& & $; 88 ; 89$ & 13 \\
\hline III & $72-87$ & $80 ; 87 ; 86 ; 85 ; 85 ; 82 ;$ & \\
& & $84 ; 85 ; 73 ; 87$ & 10 \\
\hline & Jumlah & & 26 \\
\hline
\end{tabular}

99Muhammad Furhan Qudrotullah, Buku Statistik, (Suka Press 2013), hlm. 46 ${ }^{100}$ Ibid 
Aziz Abdullah dan Purwoko : Pembelajaran Bahasa Arab Dengan Metode Al-'Arabiya Baina Yadaika Di Ma'had Ali Bin Abi Thalib Universitas Muhammadiyah Yogyakarta

Tabel 8 :

Kategori Skor Pembelajaran Bahasa Arab Metode Al-'Arobiyah Baina Yadaika di Mustawa Tamhidy Ma'had Ali Bin Abi Thalib

\begin{tabular}{|l|c|c|c|c|c|}
\hline No & Interval & Kategori & Frekuensi & Responden & Persentase \\
\hline I & $102-115$ & Sangat Baik & 3 & 26 & $11,54 \%$ \\
\hline II & $88-101$ & Baik & 13 & 26 & $50 \%$ \\
\hline II & $72-87$ & Kurang Baik & 10 & 26 & $38,46 \%$ \\
\hline & Jumlah & & & & $100 \%$ \\
\hline
\end{tabular}

Berdasarkan tabel tersebut dapat diketahui bahwa pembelajaran bahasa arab dengan metode Al-'Arobiyah Baina Yadaika di Mustawa Tamhidy Ma'had Ali Bin Abi Thalib Universitas Muhammadiyah Yogyakarta dengan kategori sangat baik adalah 11,54\%, kategori baik adalah 50\% dan kategori kurang baik adalah 38,46\%.101

Berdasarkan hasil perhitungan tersebut menunjukkan bahwa prosentase skor tertinggi adalah 50\% yang merupakan interval kategori baik, sehingga dapat diambil kesimpulan bahwa pembelajaran bahasa arab dengan metode Al-Arobiyah Baina Yadaika di Mustawa Tamhidy Ma'had Ali Bin Abi Tholib adalah baik. ${ }^{102}$

101 Ibid

102 Hasil Angket pada tanggal 12 Oktober 2015 
Aziz Abdullah dan Purwoko : Pembelajaran Bahasa Arab Dengan Metode Al-'Arabiya Baina Yadaika Di Ma'had Ali Bin Abi Thalib Universitas Muhammadiyah Yogyakarta

3. Faktor Pendukung dan Faktor Penghambat

Faktor pendukung pembelajaran bahasa arab dengan metode Al-'Arobiyah Baina Yadaika di Mustawa Tamhidy Ma'had Ali Bin Abi Tholib sebagai berikut :103

a. Lokasi dan lingkungan ma'had yang kondusif dan nyaman di komplek masjid Ahmad Dahlan Universitas Muhamadiyah Yogyakarta, tentu sangat mendukung mahasiswa untuk belajar.

b. Buku Al-'Arobiyah Baina Yadaika yang mudah dimiliki mahasiswa dan mereka senang dengan materi buku tersebut.

c. Jumlah ideal mahasiswa dalam satu kelas adalah 15 sampai dengan 20 mahasiswa.

d. Ruangan yang kondusif dan nyaman yang membantu mahasiswa memfokuskan pelajaran.

e. Suasana kelas yang kondusif, kehadiran mahasiswa baik, interaksi antara pengajar dengan mahasiswa yang bagus, akrab dan santai. ${ }^{104}$

Faktor penghambat pembelajaran bahasa arab dengan metode Al-'Arobiyah Baina Yadaika di Mustawa Tamhidy Ma'had Ali Bin Abi Tholib sebagai berikut : November 2015

${ }^{103}$ Hasil Wawancara dengan Ustadz Fahri Imanul Haq Lc, M.Si tanggal 23 104 Hasil Wawancara dengan Ustadz Muhammad Iqbal Lc, tanggal 26 Oktober 2015

170 Jurnal Komunikasi dan Pendidikan Islam, Volume 1, Nomor 1, Juni 2018 
Aziz Abdullah dan Purwoko : Pembelajaran Bahasa Arab Dengan Metode Al-'Arabiya Baina Yadaika Di Ma'had Ali Bin Abi Thalib Universitas Muhammadiyah Yogyakarta

a. Kurangnya fasilitas yang digunakan sehingga pembelajaran bahasa arabdalam penguasaan kurang maksimal.

b. Kurangnya media pendukung dalam pembelajaran bahasa arab dengan metode Al-'Arobiyah Baina Yadaika di Mustawa Tamhidy Ma'had Ali Bin Abi Tholib.

c. Tidak fokusnya mahasiswa dalam belajar saja tapi banyak mahasiswa yang sambil kerja ataupun kuliah. ${ }^{105}$

d. Mahasiswa kurang memperhatikan pengajar sehingga kurang menyerap ilmu, seperti mahasiswa yang sering tidak hadir sehingga terputus maklumat, dan mahasiswa yang pasif. ${ }^{106}$

\section{H. Kesimpulan}

Berdasarkan analisis data maka dapat diambil sebuah kesimpulan tentang pembelajaran bahasa arab dengan metode Al-Arabiyah Baina Yadaika di Ma'had Ali bin Abi Thalib Universitas Muhammadiyah Yogyakarta, dari hasil penelitian diatas dapat diambil kesimpulan sebagai berikut :

1. Pembelajaran bahasa arab dengan metode Al-Arobiyah Baina Yadaika di Mustawa Tamhidy Ma'had Ali Bin Abi Thalib adalah untuk pemula, yang belum bisa berbahasa November 2015

105Hasil Wawancara dengan Ustadz Fahri Imanul Haq Lc, M.Si tanggal 23 ${ }^{106}$ Hasil Wawancara dengan Ustadz Muhammad Iqbal Lc, tanggal 26 Oktober 2015 
Aziz Abdullah dan Purwoko : Pembelajaran Bahasa Arab Dengan Metode Al-'Arabiya Baina Yadaika Di Ma'had Ali Bin Abi Thalib Universitas Muhammadiyah Yogyakarta

arab, pembelajarannya dibagi dua kelompok yaitu kelompok khiwar (muhadatsah) dan kelompok tadribat.Tujuannya untuk mewujudkan kemahiran dan keterampilan bahasa arab aktif yang meliputi :
a. Kemahiran menyimak (fahmu al-masmu')
b. Kemahiran membaca (qira'ah)
c. Kemahiran berbicara (muhadatsah)
d. Kemahiran menulis (kitabah)

2. Hasil yang dicapai dalam pembelajaran bahasa arab dengan metode Al-Arabiyah Baina Yadaika di Ma'had Ali bin Abi Thalib Universitas Muhammadiyah Yogyakarta adalah baik berdasarkan analisis data yang menunjukkan nilai presentasi kategori baik adalah paling tinggi yaitu 50\%, sedangkan kategori sangat baik sebesar 11,54\% dan kategori kurang baik adalah $38,46 \%$.

3. Faktor Pendukungnya adalah lokasi dan lingkungan ma'had yang kondusif dan nyaman dikomplek masjid Ahmad Dahlan Universitas Muhamadiyah Yogyakarta, tentu sangat mendukung mahasiswa untuk belajar.Buku Al-'Arobiyah Baina Yadaika yang mudah dimiliki mahasiswa dan mereka senang dengan materi buku tersebut. Jumlah ideal mahasiswa dalam satu kelas adalah 15 sampai dengan 20 mahasiswa. Ruangan yang kondusif dan nyaman yang membantu mahasiswa memfokuskan pelajaran. Suasana kelas yang kondusif, kehadiran 
mahasiswa baik, interaksi antara pengajar dengan mahasiswa yang bagus, akrab dan santai.

4. Faktor Penghambatnya adalah karena kurangnya fasilitas yang digunakan dalam pembelajaran bahasa arab serta penguasaannya kurang maksimal.Selain itu kurangnya media-media pendukung dalam pembelajaran bahasa arab dengan metode Al-'Arobiyah Baina Yadaika.

5. Tidak fokusnya mahasiswa dalam belajar saja karena banyak mahasiswa yang sambil kerja ataupun kuliah di tempat lain juga menghambat belajar.Mahasiswa kurang memperhatikan pengajar sehingga kurang menyerap ilmu, seperti mahasiswa yang sering tidak hadir dan tidak aktifdikelas. 
Aziz Abdullah dan Purwoko : Pembelajaran Bahasa Arab Dengan Metode Al-'Arabiya Baina Yadaika Di Ma'had Ali Bin Abi Thalib Universitas Muhammadiyah Yogyakarta

\section{DAFTAR PUSTAKA}

Abdul Hamid, Uril Baharudin, Bisri Musthofa. 2008. Metode Pengajaran Bahasa Arab,. UIN Malang Press.

Abdul Majid. 1981. Pembelajaran bahasa. Bandung : PT. Remaja Rosdakarya.

Abdurrahman bin Ibrahim Al-Fauzan. 2002. Buku Panduan Belajar Bahasa Arab 'Al 'Arabiyah Baina Yadaik, Jakarta : PT. Future Media Gate FMG.

. 2007. Al 'Arabiyah Baina Yadaik (Kitaabut Thoolib), Riyadh : Maktabah Al-Malik Fahd.

Acep Hermawan. 2001.Metodologi Pembelajaran Bahasa Arab.Bandung : PT Remaja Rosdakarya.

Departemen Agama RI. 2009. Al-Qur'an Tajwid dan Terjemahannya Dilengkapi dengan Asbabun Nuzul Dan Hadits Shahih, Bogor : Sygma Examedia Arkanlema.

Imam Makruf. 2009. Strategi Pembelajaran bahasa Arab, Semarang: Need's Press.

Muhammad Abdul Hamid dkk. 2008. Pembelajaran Bahasa Arab: Pendekatan, Metode, Strategi, Materi dan Media. Malang: UIN Malang Press.

Muhammad Furhan Qudrotullah. 2013. Buku Statistik, Yogyakarta : Suka Press

Musthafa Al-Ghulayani. 1991. Jami' Ad-Durus Al-'Arobiyah, Semarang : CV. Asy-Syifa'.

Oemar Hamalik. 2008. Proses Belajar Mengajar, Jakarta: PT. Bumi Aksara. 
Aziz Abdullah dan Purwoko : Pembelajaran Bahasa Arab Dengan Metode Al-'Arabiya Baina Yadaika Di Ma'had Ali Bin Abi Thalib Universitas Muhammadiyah Yogyakarta

Sudijono Anas. 2005. Pengantar Statistik Pendidikan, Jakarta: Rajawali Pers.

Suharsimi Arikunto. 2007. Prosedur Penelitian, Suatu Pendekatan Praktek, Jakarta: Rineka Cipta.

Sutrisno Hadi. 1990. Metodologi Research II. Yogyakarta : Andi Offset 